\title{
PEMANFAATAN TANAMAN SEBAGAI OBAT OLEH MASYARAKAT DESA KARANG DUKUH KECAMATAN BELAWANG KABUPATEN BARITO KUALA
}

\author{
Endah lestari, Lagiono \\ Program Studi Pendidikan Biologi STKIP PGRI BANJARMASIN \\ endahlestary95@gmail.com
}

\begin{abstract}
ABSTRAK
Tanaman Obat memiliki ribuan jenis spesies, dari total sekitar 40.000 jenis tumbuhan obat yang telah dikenal di dunia, 30.000-nya disinyalir berada di Indonesia. Jumlah tersebut mewakili 90\% dari tanaman obat yang terdapat di wilayah Asia. Tujuan penelitian adalah untuk mengetahui pemanfaatan tanaman sebagai obat oleh masyarakat Desa Karang Dukuh Kecamatan Belawang Kabupaten Barito Kuala yang nanti hasil penelitian ini dapat digunakan sebagai bahan pembelajaran Biologi di Sekolah.

Metode penelitian yang digunakan adalah snowball sampling dengan cara observasi dan wawancara untuk mengetahui jenis tanaman obat yang ada di perkarangan Desa Karang Dukuh. Pengambilan sampel diambil dari hasil wawancara Masyarakat Desa Karang Dukuh. Hasil penelitian menunjukan tanaman obat yang terdapat pada perkarangan Desa Karang Dukuh Kecamatan Belawang Kabupaten Barito Kuala sebanyak 25 jenis yang termasuk kedalam 16 famili. Jenis tanaman yang digunakan adalah Jahe Merah, Janar, Cocor Bebek, lidah Buaya, Kencur, Temulawak, Seledri, Sukun, Sawo, Kembang Sepatu, Kumis Kucing Ciplukan, lamtoro, Kemangi, luntas, Mengkudu, Sirih, Ketepeng Cina, Pacar Air, Patah Tulang, Salam, Kastela, Sambiloto, Rosella, Brotowali, Tetpai masyarakat sering menggunakan tanaman patah tulang, karena mereka sering merasakan sakit gigi, dan caranya memasukan getah patang tulang ke dalam gigi yang berlubang dan jangan sampai terkena gigi yang tidak sakit. Karena tanaman patah tulang sangat mudah untuk didapat.
\end{abstract}

Kata Kunci ; Pemanfaatan; Tanaman; sebagai Obat.

\section{PENDAHULUAN}

Tanaman obat memiliki ribuan jenis spesies. Dari total sekitar 40.000 jenis tumbuhtumbuhan obat yang telah dikenal di dunia, 30.000-nya disinyalir berada di Indonesia. Jumlah tersebut mewakili $90 \%$ dari tanaman obat yang terdapat di wilayah Asia. Dari jumlah tersebut, 25\% diantaranya atau sekitar 7.500 jenis sudah diketahui memiliki khasiat herbal atau tanaman obat. Namun hanya 1.200 jenis tanaman yang sudah dimanfaatkan untuk bahan baku obat-obatan herbal atau jamu.

Indonesia sangat kaya dengan berbagai spesies flora. Sebanyak 40.000 jenis flora yang tumbuh di dunia, 30.000 di antaranya tumbuhan di Indonesia. Sekitar 26\% flora di Indonesia telah dibudidayakan dan sisanya masih tumbuh secara liar di hutan-hutan. Indonesia memiliki sekitar 17\% jumlah spesies yang ada di dunia. Hutan tropis yang sangat luar beserta keanekaragaman hayati yang ada di dalaamnya merupakan sumber daya alam yang takter nilai harganya. Indonesia dikenal sebagai gudang tumbuhan obat (herbal), sehingga mendapat sebutan live laboratory.

Indonesia dikenal sebagai negara yang mempunyai keanekaragaman suku bangsa terbesar di dunia. Tercatat kurang lebih 159 suku bangsa yang mendiami ribuan kepulauan di seluruh Nusantara. Keanekaragaman suku bangsa ini menyebabkan perbedaan dalam pemanfaatan tumbuhan baik dalam bidang ekosistem, spiritual, nilai-nilai budaya, kesehatan, kecantikan bahkan pengobatan penyakit. 
Tumbuhan obat adalah bahan atau ramuan bahan alam yang berasal dari tumbuhan, mineral, hewan atau campuran bahan tersebut yang secara tradisional yang telah digunakan untuk pengobatan berdasarkan pengalaman.

Pengetahuan tentang tumbuhan berkhasiat obat ini sudah lama dimiliki oleh nenek moyang kita dan hingga saat ini telah banyak yang terbukti secara ilmiah. Pemanfaatan tumbuhan obat Indonesia akan terus meningkat mengingat kuatnya keterkaitan bangsa Indonesia terhadap tradisi kebudayaan memakai jamu.

Tanaman obat tidak hanya dapat digunakan sebagai obat tradisional dan konsumsi rumah tangga, namun juga dapat dikembangkan dan diolah untuk berbagai macam kebutuhan, seperti industri, makanan/minuman. Sebagai bahan pembuatan kosmetik dan juga digunakan dalam industri spa tradisional. Pemanfaatan tanaman obat ini semakin berkembang seiring dengan mulai berkembangnya produk herbal di tengah-tengah masyarakat modern dan juga peran media dalam meningkatkan citra produk herbal ke masyarakat

\section{METODE PENELITIAN}

Jenis dalam penelitian ini bersifat deskriptif dengan teknik pengambilan sampel secara observasi dan wawancara. Teknik observasi yang dilakukan adalah terjun langsung kelapangan dalam pengamatan, sedangkan wawancara dilakukan secara langsung kepada masyarakat.

Tempat penelitian di Desa Karang Dukuh Kecamatan Belawang Kabupaten Barito Kuala. Waktu yang diperlukan mulai dari tahap pembuatan proposal sampai sidang skripsi memakan waktu 6 bulan.

Populasi dalam penelitian ini adalah semua yang di ketahui jenis tanaman obat yang ada di Desa Karang Dukuh Kecamatan Belawang Kabupaten Barito Kuala. Sampel penelitian adalah jenis tanaman obat yang di manfaatkan.

Teknik pengambilan sampel dilakukan dengan cara menggunakan snowball sampling untuk mengetahui jenis tanaman obat yang dimanfaatkan.

\section{HASIL DAN PEMBAHASAN}

Berdasarkan hasil penelitian tanaman obat yang ada di Desa Karang Dukuh Kecamatan Belawang Kabupaten Barito Kuala ditemukan jenis-jenis tanaman obat yang dilakukan secara observasi dan wawancara.

\begin{tabular}{|c|l|l|l|r|l|}
\hline No. & $\begin{array}{l}\text { Jenis tanaman obat } \\
\text { yang ditemukan }\end{array}$ & Nama Ilmiah & Nama Daerah & HO & HW \\
\hline 1. & Jahe merah & $\begin{array}{l}\text { Zingiber officinale } \\
\text { Linn }\end{array}$ & Jahe merah & $\checkmark$ & \\
\hline 2. & Janar & Curcuma domestica & Kunir & $\checkmark$ & \\
\hline 3. & Cocor bebek & $\begin{array}{l}\text { Kalanchoe pinnata } \\
\text { Pers }\end{array}$ & Cocor bebek & $\checkmark$ & \\
\hline 4. & Lidah buaya & Aloe vera linn & Lidah buaya & $\checkmark$ & \\
\hline 5. & Kencur & Kaempferia galanga L & Kencur & $\checkmark$ & \\
\hline 6. & Temulawak & $\begin{array}{l}\text { Curcuma xanthorrhiza } \\
\text { Roxburgh }\end{array}$ & Temulawak & $\checkmark$ & \\
\hline 7. & Daun sop & Apium graveolens L & Seledri & $\checkmark$ & \\
\hline
\end{tabular}




\begin{tabular}{|c|l|l|l|r|c|}
\hline 8. & Sukun & Artocarpus altilis & Sukun & $\checkmark$ & \\
\hline 9. & Sawo & Manilkara zapota & Sawo & $\checkmark$ & \\
\hline 10. & Kembang sepatu & $\begin{array}{l}\text { Hibiscur rosa sinensis } \\
\text { L }\end{array}$ & Kembang sepatu & $\checkmark$ & \\
\hline 11. & Kumis kucing & Orthosiphon aristatus & Kumis kucing & $\checkmark$ & \\
\hline 12. & Ciplukan & Physalis angulata L. & Cipluan & $\checkmark$ & \\
\hline 13. & Lamtoro & $\begin{array}{l}\text { Leucaena leucocephala } \\
\text { L. }\end{array}$ & Lamtoro & $\checkmark$ & \\
\hline 14. & Kemangi & Ocinum citriodorum & Kemangi & $\checkmark$ & \\
\hline 15. & Luntas & Pluchea indica & Luntas & $\checkmark$ & \\
\hline 16. & Mengkudu & Morinda citriffolia & Mengkudu & $\checkmark$ & \\
\hline 17. & Sirih & Piper betle & Sirih & $\checkmark$ & \\
\hline 18. & Ketepeng cina & Cassia alata L. & Ketepeng & $\checkmark$ & \\
\hline 19. & Pacar air & Impatiens balsamina L & Pacar air & $\checkmark$ & \\
\hline 20. & Patah tulang & Euphorbia tirucalli L & Patah tulang & $\checkmark$ & \\
\hline 21. & Salam & Syzygium polyanthum & Kencing manis & & $\checkmark$ \\
\hline 22. & Kastela & Carica papaya & Peredam haid & & $\checkmark$ \\
\hline 23. & Sambiloto & $\begin{array}{l}\text { Andrographispaniculat } \\
\text { a ness }\end{array}$ & Darah tinggi & & $\checkmark$ \\
\hline 24. & Rosella & & $\begin{array}{l}\text { Menurunkan } \\
\text { tekanan darah }\end{array}$ & & $\checkmark$ \\
\hline 25. & Brotowali & Tinospora crispa & Diabetes & & $\checkmark$ \\
\hline
\end{tabular}

Jenis-jenis tanaman obat berdasarkan hasil penelitian tanaman obat yang ada di Desa Karang Dukuh Kecamatan Belawang Kabupaten Barito Kuala.

\begin{tabular}{|c|c|c|c|c|c|}
\hline No & Nama ilmiah & Nama lokal & (nama famili) & $\begin{array}{c}\text { Nama } \\
\text { indonesia }\end{array}$ & Habitus \\
\hline 1. & $\begin{array}{l}\text { Zingiber } \\
\text { officinale } \\
\text { Linn }\end{array}$ & Jahe merah & Zingiberaceae & Jahe merah & Herba \\
\hline 2. & $\begin{array}{l}\text { Curcuma } \\
\text { domestica }\end{array}$ & Janar & Zingiberaceae & Kunyit & Herba \\
\hline 3. & $\begin{array}{l}\text { Kalanchoe } \\
\text { pinnata } \text { Pers }\end{array}$ & Cocor bebek & Crassulaceae & Cocor bebek & Herba \\
\hline 4. & Aloe vera linn & Lidah buaya & Asphodelaceae & lidah buaya & Semak \\
\hline 5. & $\begin{array}{l}\text { Kaempferia } \\
\text { galanga } \mathrm{L}\end{array}$ & Kencur & Zingiberaceae & Kencur & Semak \\
\hline 6 & $\begin{array}{l}\text { Curcuma } \\
\text { xanthorrhiza } \\
\text { Roxburgh }\end{array}$ & Temulawak & Zingiberaceae & Temulawak & Herba \\
\hline 7 & $\begin{array}{l}\text { Apium } \\
\text { graveolens L. }\end{array}$ & Daun sop & Apiaceae & Seledri & Semak \\
\hline 8 & $\begin{array}{l}\text { Artocarpus } \\
\text { altilis }\end{array}$ & Sukun & Apiaceae & Sukun & Pohon \\
\hline 9 & $\begin{array}{l}\text { Manilkara } \\
\text { zapota }\end{array}$ & Sawo & Sapotacea & Sawo & Pohon \\
\hline 10 & $\begin{array}{ll}\text { Hibiscur } & \text { rosa } \\
\text { sinensis L } & \\
\end{array}$ & $\begin{array}{l}\text { Kembang } \\
\text { sepatu }\end{array}$ & Sapotaceae & $\begin{array}{l}\text { Kembang } \\
\text { sepatu }\end{array}$ & Perdu \\
\hline 11 & $\begin{array}{l}\text { Orthosiphon } \\
\text { aristatus }\end{array}$ & Kumis kucing & Lamiaceae & $\begin{array}{l}\text { Kumis } \\
\text { kucing }\end{array}$ & Pohon \\
\hline 12 & $\begin{array}{l}\text { Physalis } \\
\text { angulata L. }\end{array}$ & Lalipang & Lamiaceae & Ciplukan & Semak \\
\hline 13 & $\begin{array}{l}\text { Leucaena } \\
\text { leucocephala } \mathrm{L}\end{array}$ & Lamtoro & Fabaceae & Lamtoro & Perdu \\
\hline
\end{tabular}


Pemanfaatan Tanaman Sebagai Obat Oleh Masyarakat Desa Karang Dukuh Kecamatan Belawang Kabupaten Barito Kuala

\begin{tabular}{|c|c|c|c|c|c|}
\hline 14 & $\begin{array}{l}\text { Ocinum } \\
\text { citriodorum }\end{array}$ & Kemangi & Lamiaceae & Kemangi & Herba \\
\hline 15 & Pluchea indica & Luntas & Piparaceae & Beluntas & Perdu \\
\hline 16 & $\begin{array}{l}\text { Morinda } \\
\text { citriffolia } \mathrm{L}\end{array}$ & Mengkudu & Rubiaceae & Mengkudu & Pohon \\
\hline 17 & Piper betle & Sirih & Piparaceae & Sirih & Herba \\
\hline 18 & Cassia alata $\mathrm{L}$. & Ketepeng cina & Leguminosae & $\begin{array}{l}\text { Ketepeng } \\
\text { cina }\end{array}$ & Pohon \\
\hline 19 & $\begin{array}{l}\text { Impatiens } \\
\text { balsamina L }\end{array}$ & Pacar air & Combretaceae & Pacar air & Herba \\
\hline 20 & $\begin{array}{l}\text { Euphorbia } \\
\text { tirucalli L. }\end{array}$ & Patah tulang & Euphorbiacea & Patah tulang & Perdu \\
\hline 21 & $\begin{array}{l}\text { Syzygium } \\
\text { polyanthum }\end{array}$ & Salam & Myrtaceae & Salam & Pohon \\
\hline 22 & Carica papaya & Kastela & Cacicaceae & Pepaya & Pohon \\
\hline 23 & $\begin{array}{l}\text { Andrographispa } \\
\text { niculata ness }\end{array}$ & Sambiloto & Acanthacea & Sambiloto & Herba \\
\hline 24 & $\begin{array}{l}\text { Syzygium } \\
\text { polyanthum }\end{array}$ & Rosella & Malvaceae & Rosella & Semak \\
\hline 25 & $\begin{array}{l}\text { Tinospora } \\
\text { crispa }\end{array}$ & Brotowali & Euphorbiacea & Brotowali & Liana \\
\hline
\end{tabular}

Cara penggunaan tumbuhan Obat berdasarkan hasil penelitian tanaman obat yang ada di Desa Karang Dukuh Kecamatan Belawang Kabupaten Barito Kuala

\begin{tabular}{|c|c|c|c|c|}
\hline No. & $\begin{array}{l}\text { Jenis tanaman } \\
\text { Obat }\end{array}$ & Penyembuhan & $\begin{array}{l}\text { Cara } \\
\text { penggunaan }\end{array}$ & $\begin{array}{l}\text { Bagian yang } \\
\text { digunakan }\end{array}$ \\
\hline 1. & Jahe merah & Batuk & $\begin{array}{l}\text { Parut, peras, } \\
\text { minum. }\end{array}$ & Rimpang \\
\hline 2. & Janar & Sesak napas & $\begin{array}{l}\text { Parut, peras, } \\
\text { minum }\end{array}$ & Rimpang \\
\hline 3. & Cocor bebek & Panas & $\begin{array}{l}\text { Digiling, } \\
\text { ditempelkan }\end{array}$ & Daun \\
\hline 4. & Lidah buaya & Tersiram air panas & Ditempelkan, & Daun \\
\hline 5. & Kencur & Batuk & Dikupas, kunyah, & Rimpang \\
\hline 6. & Temulawak & Sakit Mag & Rebus, diminum & Rimpang \\
\hline 7. & Daun sop & Darah tinggi & Dipipis, diminum & $\begin{array}{l}\text { Seluruh bagian } \\
\text { tumbuhan }\end{array}$ \\
\hline 8. & Sukun & $\begin{array}{l}\text { Menurunkan } \\
\text { kolestrol }\end{array}$ & Seduh, diminum & Daun \\
\hline 9. & Sawo & Diare & Diparut, diminum & Buah \\
\hline 10. & Kembang sepatu & Panas & Diremas, ditempel & Daun \\
\hline 11. & Kumis kucing & Ginjal & direbus, diminum. & Daun \\
\hline 12. & Ciplukan & Darah tinggi & Direbus, diminum & Buah \\
\hline 13. & Lamtoro & Luka & $\begin{array}{l}\text { Haluskan, } \\
\text { ditempelkan }\end{array}$ & Daun \\
\hline 14. & Kemangi & Panu & $\begin{array}{l}\text { Dihaluskan, } \\
\text { oleskan. }\end{array}$ & Daun \\
\hline 15. & Luntas & $\begin{array}{l}\text { Menghilangkan bau } \\
\text { badan }\end{array}$ & Dimakan & Daun \\
\hline 16. & Mengkudu & $\begin{array}{l}\text { Menghilangkan } \\
\text { gondok }\end{array}$ & $\begin{array}{l}\text { Di tali, } \text { di } \\
\text { kalungkan. }\end{array}$ & Buah \\
\hline 17. & Sirih & Asam urat & $\begin{array}{l}\text { Direbus, } \\
\text { diminum. }\end{array}$ & Daun \\
\hline 18. & Ketepeng cina & Panu & $\begin{array}{l}\text { Rebus, } \\
\text { digosokkan. }\end{array}$ & Daun \\
\hline
\end{tabular}




\begin{tabular}{|l|l|l|l|l|}
\hline 19. & Pacar air & Bisul & $\begin{array}{l}\text { Dihaluskan, } \\
\text { ditempel. }\end{array}$ & Daun \\
\hline 20. & Patah tulang & Sakit gigi & Menempelkan. & Getah \\
\hline 21. & Salam & Kencing manis & $\begin{array}{l}\text { Rebus,saring } \\
\text { diminum. }\end{array}$ & Daun \\
\hline 22. & Kastela & Peredam haid & Direbus, diminum & Daun \\
\hline 23. & Sambiloto & Darah tinggi & Seduh, diminum. & Daun \\
\hline 24. & Rosella & $\begin{array}{l}\text { Menurunkan } \\
\text { tekanan darah }\end{array}$ & Diminum. & Bunga \\
\hline 25. & Brotowali & Diabetes & Diminum. & Batang \\
\hline
\end{tabular}

\section{SIMPULAN}

Berdasarkan hasil penelitian dan pembahasan mengenai Pemanfaatan Herbal Sebagai Tanaman Obat Keluarga Di Masyarakat Desa Karang Dukuh Kecamatan Belawang Kabupaten Barito Kuala Terdapat 25 jenis dan 17 famili tumbuhan yang dimanfaatkan sebagai obat tradisioanl oleh masyarakat Desa Karang Dukuh, yaitu: jahe merah, kunyit, cocor bebek, lidah buaya, kencur, temulawak, seledri, sukun, sawo, kembang sepatu, ciplukan, lamtoro, kemangi, beluntas, mengkudu, sirih, ketepeng cina, pacar air, patah tulang, salam, pepaya, sambiloto, rosella, brotowali. Berdasarkan hasil wawancara tumbuhan yang dimanfaatkan yaitu, jahe merah, kunyit, cocok bebek, kencur, temulawak, daun sop, sukun, sawo, kembang sepatu, kumis kucing, ciplukan, lamtoro, kemangi, luntas, mengkudu, sirih, ketepeng cina, pacar air, patah tulang. Pengolahan tumbuhan obat tradisional dilakukan dengan cara diantaranya: direbus, digosok, diremas, diusapkan.

\section{DAFTAR RUJUKAN}

Baihaqi, Ahmad dkk. 2017. Tumbuhan Obat dan Satwa Liar.Jakarta: Kehati.

Dalimartha, Setiawan. 2006. Atlas Tumbuhan Obat Indonesia Jilid 4. Jakarta: Puspa Swara, Anggota Ikapi.

Hakim, L. 2014. Etnobotani dan Manajemen Kebun-Pekarangan Rumah: Ketahanan Pangan, Kesehatan, dan Agrowisata. Malang.Selaras.

Hidayat syamsul r. 2015. Kitab Tumbuhan Obat. Bogor. Agriflo (Penebar Swadaya Grup).

Kariman, 2014. Bebas Penyakit Dengan Tanaman Ajaib. Surakarta:Open Books.

Kinho, Julianus dkk. 2011. Tumbuhan Obat Tradisional di Sulawesi Utara Jilid II. Manado:

Balai Penelitian Kehutanan Manado, Balai Penelitian Dan Pengembangan Kehutanan, Kementrian Kehutanan.

Kurdi, Aserani.2010. Bagian Dari Tanaman Yang Digunakan Untuk Obat. Skripsi. Fakultas Pertanian. Universitas Muhammadiyah. Malang.

Naesin, Muchtar T. 2017. Kenalilah Tumbuhan Obat. Jakarta: Cv Indrajaya.

Noviani, Ela dkk. 2016. Studi Etnobotani Pemanfaatan Jenis-Jenis Tumbuhan yang Digunakan sebagai Obat oleh Masyarakat Desa Pangandaran Kecamatan Pangandaran Kabupaten Pangandaran. Prosiding Seminar Nasional MIPA 2016. Prodi Biologi FMIPA Universitas Padjadjaran. 03 Maret 2018. (Online).

Nuraini nuris dini, 2014. Aneka Daun Berkhasiat Obat. Sidoarjo: Gava Media. 
Nursiyah. 2013. Studi Deskriptif Tanaman Obat Tradisional Yang Digunakan Orangtua Untuk Kesehatan Anak Usia Dini Di Gugus Melati Kecamatan Kalikanjar Kabupaten Wonosobo. Skripsi tidak diterbitkan: Universitas Negeri Malang

Purwanto, Budhi Ns. 2013a. Obat Herbal Andalan Keluarga. Surakarta: FlashBooks.

Purwanto, Budhi Ns. 2016b. Obat Herbal Andalan Keluarga. Surakarta: FlashBooks.

Prasesetyono, Dwi S. 2012. A-Z Daftar Tanaman Obat Ampuh di Sekitar Kita. Jakarta Selatan: FlashBooks.

Priyoto, 2014. Pengobatan herbal untuk penyakit ringan. Yogyakarta:Graha Ilmu.

Salim, Zamroni dan Munadi Ernawaati, 2017. Info Komoditi Tanaman Obat. Jakarta: Badan Pengkajian dan Pengembangan Perdagangan.

Susilowati, Eko. 2017. TOGA Tanaman Obat Keluarga. Jakarta: Cv. Sinar Cemerlang Abadi. Sulihandari hartanti. 2013. herbal sayuran dan buah ajaib. Jogjakarta:Trans Idea Publisihing. Zaman Moh Qomarus. 2009. Etnobotani tumbuhan obat di kabupaten pamekasan-madura provinsi jawa timur. Fakultas sains dan teknologi unuversitas islam negeri (UIN) maulana malik ibrahim. 